ECCOMAS

Proceedia
COMPDYN 2021

$8^{\text {th }}$ ECCOMAS Thematic Conference on Computational Methods in Structural Dynamics and Earthquake Engineering M. Papadrakakis, M. Fragiadakis (eds.) Streamed from Athens, Greece, 28 - 30 June 2021

\title{
SEISMIC FRAGILITY ANALYSIS OF RAILWAY RC BRIDGES ACCOUNTING FOR BRIDGE-TRAIN INTERACTION BASED ON A NOVEL FORMULATION FOR CONSTRAINED DYNAMICAL SYSTEMS AND A CO-SIMULATION TECHNIQUE
}

\author{
Sotiria P. Stefanidou, and Elias A. Paraskevopoulos ${ }^{2}$ \\ ${ }^{1}$ Postdoctoral Researcher, School of Civil Engineering, Aristotle University of Thessaloniki \\ Thessaloniki, 54124, Greece \\ e-mail: ssotiria@civil.auth.gr \\ ${ }^{2}$ Postdoctoral Researcher, School of Mechanical Engineering, Aristotle University of Thessaloniki \\ Thessaloniki, 54124, Greece \\ e-mail: eapcivil@gmail.com
}

\begin{abstract}
Based on past earthquake events, bridges are the most critical and usually the most vulnerable component of road and rail transport systems, while bridge damage is related to substantial direct and indirect losses. For the case of railway bridges, the estimation of seismic fragility is a rather complex and computationally demanding procedure due to the real-time interaction of the train movement and the bridge and the different failure modes of subsystems. Several methodologies are available in the literature to estimate train-bridge systems' seismic fragility, ignoring the nonlinear behavior of the bridge during earthquake loading and the different failure modes of critical components. The scope of this research paper is to propose a component-based methodology for the estimation of bridge fragility curves, considering all critical components and failure modes of subsystems. The coupled VBI (vehicle bridge interaction) is solved in a software platform using the co-simulation approach, based on a force-displacement coupling technique and a Gauss-Seidel communication pattern. The co-simulation implementation, i.e., the orchestrator and the functional mockup units (FMUs), were developed in the environment of PyFMI. The vehicle-rail system is solved using a $C++$ tailor-made code based on a novel mathematical formulation of constrained dynamical systems with a set of pure ordinary differential equations and is wrapped in an independent FMU. The inelastic bridge model is developed and solved using OpenSees.py, which is wrapped in an independent FMU. Also, an ad-hoc software for implementing the probabilistic framework and the derivation of fragility curves is developed in Python. The methodology and the software developed are described and applied to a case study bridge of the Greek railway network, and the fragility curves are provided and discussed.
\end{abstract}

Keywords: Railway bridges, vehicle-bridge interaction (VBI), Co-simulation, fragility curves 


\section{INTRODUCTION}

Roadway and railway bridges are considered the most critical infrastructure of relevant networks exposed to multiple hazards, while damage at their critical components is related to substantial direct and indirect losses. Furthermore, decision-making for upgrade and expansion of existing roadway and railway networks should be based on detailed technical studies accounting for various social and economic parameters, infrastructure robustness and reliability data. In this context, a robust and reliable assessment of railway bridges is a valuable tool for both retrofit prioritization and investment planning. Several methodologies for seismic fragility assessment of railway bridges are available, however a detailed framework considering both the vehicle bridge-interaction and the coupled system's limit states incorporated within a fully parameterized, tailor-made software for the derivation of fragility curves has not yet been proposed.

The dynamic behavior of a train-bridge system is a coupled and complex model consisting of two main subsystems, the train, and the bridge. The train subsystem can be de-scribed as a multibody assembly and the bridge subsystem can be modeled using classical structural finite element formulations. The subsystems interact through forces between the vehicle wheels and the rail on the bridge deck. Several researchers worldwide have worked on train-bridge interaction problems integrating the train, track and bridge as a single system [1,2]. Vehicle-railbridge (VRBI) models have been introduced to analyze dynamic interaction between moving trains and railway bridges, based on the dynamic integration methods $[3,4,5,6,7]$. Due to the nonlinear interaction of subsystems, it is widely accepted that the dynamic analysis of trainbridge system during earthquakes cannot be a simple combination of bridge seismic design and train-bridge interaction calculation. Therefore, several studies have investigated the response of coupled systems under dynamic (earthquake) loading [8] as well as the seismic performance for different levels of earthquake intensity (fragility analysis) [9].

Based on the above, the scope of this paper is to propose and develop a novel methodology for the modeling and analysis of the coupled train-railway bridge system, considering an appropriate numerical discretization scheme and a solution strategy based on a co-simulation approach. Efficient modeling of the vehicle multibody assembly is proposed using a tailormade $\mathrm{C}++$ code, while the nonlinear bridge model is developed and analyzed using opensource software. Interaction between the vehicle and the bridge is proposed via an integrated approach that employs co-simulation techniques and FMI (functional mockup interface) for the communication and joint solution of subsystems in the time domain considering different time steps for analysis and selecting Gauss Seidel communication pattern. All the above are incorporated into a holistic methodology proposed herein for seismic fragility analysis of the coupled train-bridge system considering VBI, multiple critical components, and appropriate limit states that account for the running safety of high-speed trains along with the possibility for derailment. The novel methodology for fragility analysis and the relevant software developed are applied to a representative bridge of the Greek railway network, providing the subsystems' and coupled systems' fragility curves. The results are discussed and assessed, providing insight regarding seismic fragility analysis of coupled train-bridge systems and the computational framework required for their estimation.

\section{VEHICLE-BRIDGE SYSTEM INTERACTION (VBI)}

\subsection{Description of vehicle modeling}

A typical railway vehicle consists of car bodies, bogies, wheelsets and spring-damper primary and secondary suspensions. A car body is connected to the bogie frame through the sec- 
ondary suspension system, whereas the bogie is connected to the wheelsets through the primary suspension system [10]. The vehicle system can be seen as an assembly of rigid and flexible parts subjected to a set of kinematic constraints and connected through springs and dampers. This assembly constitutes a multibody system with bodies that can undergo large rotations, move at high speed, and interact with each other inducing large forces and moments. The target is to study the dynamical synergy between a moving train and a rail when the latter is attached to the bridge and may be subjected to seismic loads (and/or high lateral winds). Realistic modeling of derailment constitutes a crucial step for evaluating train running safety and should be accordingly considered.

Each vehicle of the high-speed train consists of two bogie sub-systems, connected to the car-body via an inline joint and spring-damper elements (SPDP). The latter constitutes the vertical and lateral secondary suspension system. At the lower part of each bogie, two wheelsets are placed, connected to the bogie via the axle boxes. The axle boxes are connected to the bogie with vertical and lateral spring-damper elements, forming the primary suspension system. There is a revolute joint linking the two axle boxes to the wheelset at both ends of the wheelset. The revolute joints allow the wheelsets to rotate freely to the axle boxes and vice versa. The direction of rotation is the wheelset's centerline and the wheelset-axle boxes system has eight degrees of freedom. Six of those DOFs include its rigid body motion, while the last two leave the relative rotation free between the axle boxes and the bogie, bringing the functionality of the primary suspension system. Therefore, each vehicle consists of 15 rigid bodies. The geometric cubic splines of the wheel and rail profiles and that of the track centerline generate the wheel and rail surfaces. To form the entire high-speed train a specific number of vehicles are considered, placed at a predefined distance from each other, connected through a selected type of constraint joint. A practical selection is that of the spherical joint leaving all three rotational degrees of freedom free, while the remaining three translational are unconstrained. Finally, the front vehicle has the constraint of constant linear velocity along the direction of the train movement, simulating the driving motion of the entire train assembly. The resultant contact force between the wheel and the rail can be decomposed in two component forces. The first is the normal contact force which is always perpendicular to the common tangent plane of the two surfaces at the contact point. The second component is the friction force acting in the tangent plane. This friction force is described by Kalker's linear theory.

The analysis described above is based on the assumption that the normal direction $\underline{n}$ is known. Knowing the position and orientation of the wheelset along with the analytical forms of the surfaces for the wheel and rail, a minimization problem can be formulated to determine $\underline{n}$. The minimization function is defined in the form of the square of the Euclidian distance between a point on the wheel and a point on the rail. The local minimum determines the points on the two surfaces with the shortest distance. The unit vector along the line connecting these two points provides the contact normal direction. This is the direction used to calculate the value of the contact constraint needed for the numerical integration of the equations of motion.

A dully tailored software in $\mathrm{C}++$ is developed to apply the methodology described above for the vehicle analysis. The numerical algorithm for the solution of the constrained multibody system is based on the methodogy developed in [11] and [12]. The software is wrapped in an FMU and is used within the proposed co-simulation framework for the analysis of the coupled vehicle and bridge system for earthquake loading. 


\subsection{Description of bridge modeling}

The bridge structure is modeled using an open-source FEM program, OpenSees.py [13]. The detailed inelastic model of the bridge system is developed, considering all critical parameters and boundary conditions. The deck is commonly prestressed and intended to remain elastic during earthquake loading; therefore, it is modeled using elastic beam elements with the relevant properties. Bridge piers are modeled using inelastic beam-colum elements considering concentrated plastic hinges at pier bottom for the case of cantilever piers and at pier top and bottom for multicolumn piers or piers with monolithic pier-to-deck connection. Based on the results of moment-curvature analysis the secant stiffness of the fully cracked section at yield $\left(E_{\text {eff }}=\mathrm{My}_{\mathrm{y}} / \varphi_{\mathrm{y}}\right)$ is estimated and used for the consideration of cracked elastic pier section. Regarding bearings of railway bridges, it is noted that elastomeric bearings are commonly used for the support of bridge deck on piers and seat-type abutments, while the use of pot bearings and stoppers, lead rubber bearings (with increased damping) and isolation devices are also common. For the modeling of bearings, either the linear effective stiffness or the nonlinear hysteretic behavior may be considered with the parameters calculated based on literature recommendations [14], [15], etc. Regarding pier shallow or pile foundation, linear or nonlinear springs are used for the modeling of soil-structure-interaction (SSI), playing an important role in both component and system seismic performance and fragility, as mentioned in [16]. Piles are modeled using elastic beam-column elements, while vertical (friction) and horizontal ( $\mathrm{p}-\mathrm{y})$ springs are calculated considering SSI. Modeling of boundary conditions at abutment location is crucial; therefore both the gap in the longitudinal direction and the inelastic abutment-embankment system behavior (described in detail in [17] are modeled. It should be highlighted that for the case of railway bridges there is no gap in the transverse direction, in order to prevent derailment phenomena. Response history analysis of the inelastic bridge model is performed using OpenSees.py, in order to calculate inelastic bridge responses and bridge fragility.

\section{EARTHQUAKE ANALYSIS CONSIDERING VBI PROPOSING A CO- SIMULATION APPROACH}

Coupled simulation or co-simulation has been proposed as a solution to overcome the challenges emerging in complex, coupled engineering systems. The holistic problem is being broken down into two or more individual subsystems and the coupling variables between the subsystems could be either in force terms (applied-force coupling), or in force-kinematic terms (displacement-displacement $(\mathrm{X}-\mathrm{X})$ and displacement-force (X-T) respectively) [18]. The co-simulation process is being carried out by a third simulator, named orchestrator, that is responsible for the integration, coupling, and communication between subsystems. The orchestrator leads each co-simulation step (communication interval), exchanges variables with the subsystems simulators, and checks the coupling conditions (convergence).

Regarding the communication scheme, the Gauss-Seidel (serial) communication scheme is proposed for the solution of the vehicle(train)-bridge system in the time domain. Applying an iterative Gauss-Seidel approach, the vehicle subdomain is first solved for the communication interval $\mathrm{H}$ (starting point $\mathrm{T}_{\mathrm{N}}=\mathrm{t}_{0}$,tr), assuming a known solution for the bridge subdomain. The vehicle subdomain is integrated until the next communication step, i.e. $T_{N+1}=t_{1}$,tr. At this time point, the output variables of the vehicle subdomain are being used by the orchestrator in order to calculate new inputs for the bridge subdomain. The bridge subdomain is solved until $\mathrm{T}_{\mathrm{N}+1}=\mathrm{t}_{1, \text { br }}$ (starting point $\mathrm{T}_{\mathrm{N}}=\mathrm{t}_{0, \mathrm{rr}}$ ). The process described above is repeated until the coupling conditions are satisfied (convergence) and the co-simulation can proceed to the next communication point. The vehicle subdomain is solved using a multibody dynamics method devel- 
oped at the Laboratory of Machine Dynamics (AUTh), whereas the bridge subdomain is solved via Opensees, a general FEM open-source code. The coupled vehicle-bridge systems' analysis procedure is described in Figure 1, explaining the analysis of every subsystem at every distinct step and the communication pattern.

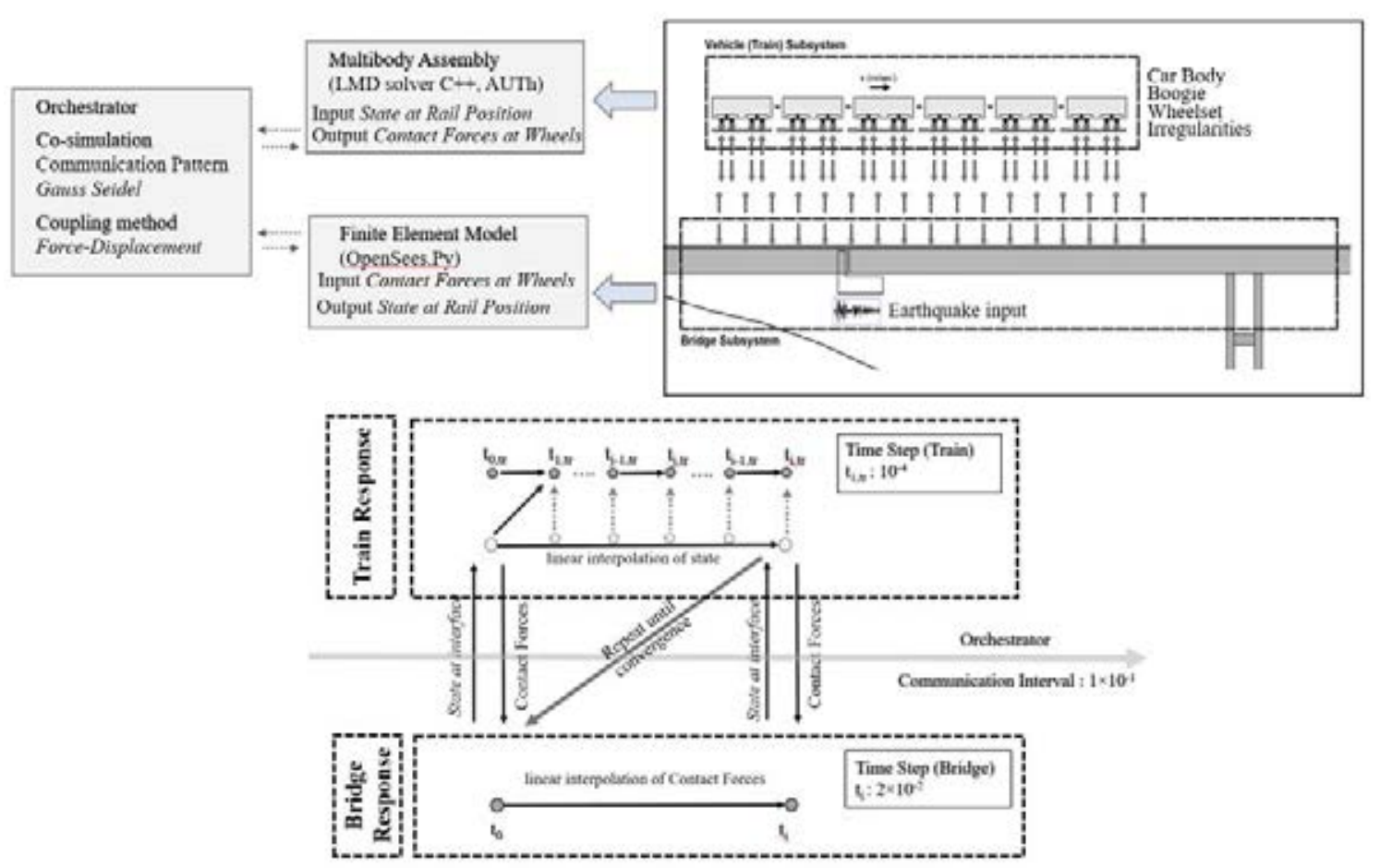

Figure 1: Outline of the methodology for dynamic high-speed train -bridge interaction

\section{SEISMIC FRAGILITY ANALYSIS OF COUPLED RAILWAY BRIDGE SYSTEMS CONSIDERING VBI}

The framework proposed for seismic fragility analysis of bridges is based on analysis results of the coupled vehicle-bridge system for different levels of earthquake intensity, estimating the probability of damage of critical bridge components and the vehicle for various limit states (minor damage to collapse) [10]. The methodology proposed is outlined in Figure 2.

For the estimation of vehicle subsystem fragility, serviceability and ultimate limit state thresholds are defined, based on the recommendations of EN1990-prANNEX A2, (2001) and BS EN 14363: (2016), as described in Table 1. The vehicle limit states proposed consider vehicle stability (LS1), the dynamic performance of the bridge (LS2) and vehicle safety (derailment LS3 \&4) (Table 1). The vehicle subsystem properties (i.e., number of boogies), speed, and time step that the vehicle enters the bridge are initially defined, and analysis of the subsystem is performed considering real-time vehicle-bridge interaction via co-simulation techniques. The threshold values are compared to the ones monitored at the vehicle during the coupled system analysis for the selected earthquake ground motions to estimate the probability of exceedance and plot the relevant fragility curves (Figure 2).

Regarding the railway bridge subsystem fragility estimation, the engineering demand parameters and their threshold values are initially defined at component level for different limit states, as described in detail in [17]. The structural type of the railway bridge is selected, along with varying properties (random variables selection), for probabilistic treatment and 
derivation of bridge samples using Latin Hypercube Sampling (LHS). The bridge samples are analysed considering real-time train-bridge interaction for accelerograms of varying intensity $(0.1 \sim 1.0 \mathrm{~g})$, selected applying Multiple Stripe Analysis (details for Multiple Stipe Analysis and accelerogram selection are available in [16]). The engineering demand parameters values at component control points are monitored to estimate the probability of limit state threshold exceedance and plot fragility curves at component and system level. Based on the above, fragility curves for the subsystems and the coupled system are proposed accounting for series connection and complete correlation of critical components.

\begin{tabular}{|c|c|c|c|c|c|c|c|c|}
\hline & \multicolumn{3}{|c|}{$\begin{array}{l}\text { Criteria for train running stabil- } \\
\text { ity }\end{array}$} & \multicolumn{3}{|c|}{$\begin{array}{l}\text { Criteria for bridge dynamic } \\
\text { performance }\end{array}$} & \multicolumn{2}{|c|}{$\begin{array}{c}\text { Criteria for train running } \\
\text { safety }\end{array}$} \\
\hline & $\begin{array}{l}\text { Lateral } \\
\text { accel. } \\
\text { (boogie) }\end{array}$ & $\begin{array}{c}\text { Lateral } \\
\text { accel. } \\
\text { (veh.body) }\end{array}$ & $\begin{array}{c}\text { Vertical } \\
\text { accel. } \\
\text { (veh.body) }\end{array}$ & $\begin{array}{l}\text { Accel- } \\
\text { eration }\end{array}$ & $\begin{array}{r}\text { Transvers } \\
\text { mation \& } v \\
\text { of de }\end{array}$ & $\begin{array}{l}\text { lefor- } \\
\text { ration }\end{array}$ & $\begin{array}{c}\text { Overturn } \\
\text { Coefficient }\end{array}$ & $\begin{array}{l}\text { Overturn } \\
\text { Criterion }\end{array}$ \\
\hline 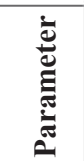 & $\begin{array}{l}\text { Accel. } \\
\left(\mathrm{m} / \mathrm{s}^{2}\right)\end{array}$ & $\begin{array}{l}\text { Accel. } \\
\left(\mathrm{m} / \mathrm{s}^{2}\right)\end{array}$ & $\begin{array}{l}\text { Accel. } \\
\left(\mathrm{m} / \mathrm{s}^{2}\right)\end{array}$ & $\begin{array}{l}\text { Accel- } \\
\text { eration } \\
\left(\mathrm{m} / \mathrm{s}^{2}\right)\end{array}$ & \multicolumn{2}{|c|}{$\begin{array}{l}\text { Curvature }(1 / \mathrm{m}) \\
\qquad\left[r=l^{2} / 8 \cdot \delta_{h}\right]\end{array}$} & $D=P_{\mathrm{d}} / P_{\mathrm{st}}$ & $\kappa=\frac{\sum_{\text {hoogie }} Q_{j A}-\sum_{\text {hoogie }} Q_{j B}}{\sum_{\text {boogie }} Q_{j A}+\sum_{\text {hoosie }} Q_{j B}}$ \\
\hline 营 & $\begin{array}{c}12.0 \mathrm{~m} / \mathrm{s}^{2} \\
-\left(\mathrm{m}^{+} / 5 \mathrm{t}\right) \\
=11.392 \\
\mathrm{~m} / \mathrm{s}^{2}\end{array}$ & 3.0 & 5.0 & $\begin{array}{c}0.35 \mathrm{~g} \\
\left(3.5 \mathrm{~m} / \mathrm{s}^{2}\right. \\
) \text { for } \\
\text { ballast- } \\
\text { ed track }\end{array}$ & $\begin{array}{c}\begin{array}{c}\text { Speed range } \\
\left(\mathrm{km} \mathrm{h}^{-1}\right)\end{array} \\
\mathrm{V} \leq 120 \\
120 \leq \mathrm{V} \leq 200 \\
\mathrm{~V}>200 \\
\end{array}$ & $\begin{array}{c}\text { Limits } \\
1700 \\
6000 \\
14000 \\
\end{array}$ & $\begin{array}{c}0.80 \text { (for all } \\
\text { wheels at } \\
\text { the same } \\
\text { time }\end{array}$ & 1.0 \\
\hline
\end{tabular}

Table 1: Limit values for vehicle and fragility analysis of the coupled train-bridge system

For the estimation of the coupled systems' fragility curves, seismic analysis of the coupled system is performed considering earthquake loading of varying intensity $(0.1 \sim 1 \mathrm{~g})$. The analysis results are recorded at the vehicle and the bridge control points for the all the coupled (train-bridge) system samples. The values are compared to the limit state thresholds of each subsystem (and component) and statistical analysis of the results is performed estimating the mean and standard deviation of capacity over demand exceedance and, eventually, the seismic fragility curves of the vehicle and bridge subsystem. For the estimation of uncertainty in capacity and demand the methodology described in [17] is followed. The fragility curves of the coupled system are calculated assuming series connection between subsystems (vehicle and bridge) according to Eq. 1 (upper and lower bound, Zhang \&Huo, (2009)):

$$
\max _{i=1}^{n}\left[\mathrm{P}\left(\mathrm{F}_{i}\right)\right] \leq P\left(F_{\text {ssstem }}\right) \leq 1-\prod_{i=1}^{\pi}\left[1-P\left(F_{i}\right)\right]
$$

The lower bound corresponds to completely correlated components, while the upper bound assumes no correlation between components. Therefore, the coupled system's fragility lies within these two bounds and the exact value is dependent on the correlation of the component response.

\section{APPLICATION TO A CASE STUDY RAILWAY BRIDGE FOR THE ESTIMATION OF SEISMIC FRAGILITY OF THE COUPLED SYSTEM}

The methodology presented above is applied to a representative bridge of the Greek railway network with simply supported deck, using the software developed for real-time bridgevehicle analysis. A five boogies Vehicle is considered to cross the bridge during the earthquake. The vehicle is entering the bridge about $3[\mathrm{sec}]$ before the earthquake peak. Based on the coupled system analysis results, fragility analysis is performed, and fragility curves are provided for all the critical bridge components, the bridge subsystem, the vehicle subsystem and the coupled system. The effect of VBI consideration on seismic fragility of critical bridge 
components (piers and abutments since pot bearings are used in combination with stoppers, rendering the bearings a non-critical component) is evaluated providing relevant fragility curves for the cases of earthquake only analysis and earthquake analysis accounting for VBI. Moreover, the seismic fragility curves of the bridge subsystem with and without VBI consideration are provided for both longitudinal and transverse direction, highlighting the effect of VBI on the subsystem's fragility. The seismic fragility of the vehicle subsystem is also provided for both directions along with the fragility curves of the coupled (vehicle and bridge) system based on series connection assumption. The effect of the consideration or ignorance of vehicle subsystem limit states and fragility, i.e. the consideration of the coupled system instead of the bridge system solely, is evaluated and discussed.

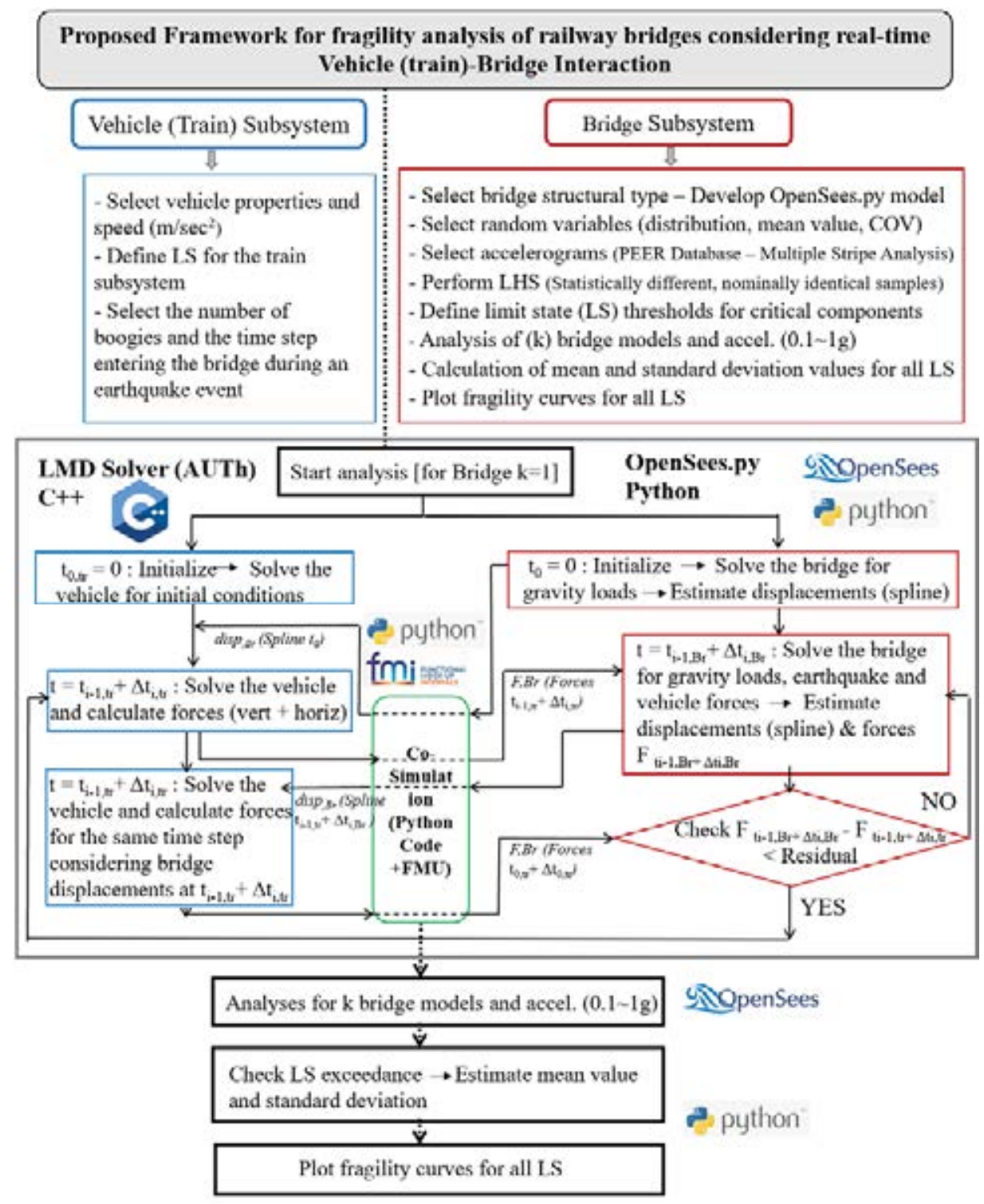

Figure 2: Outline of the methodology for dynamic high-speed train-track-bridge interaction.

The Tirothea - Domokos bridge is a two-way railway bridge of the Athens-Thessaloniki railway network, located at Central Greece, near Lamia (Figure 3). Responsible for the management of the project is ERGOSE SA, Greece. The bridge is designed for train speed equal to $\mathrm{v} \leq 200 \mathrm{~km} / \mathrm{h}$ and PGA equal to $0.24 \mathrm{~g}$, while it should be outlined that it is located at a $175 \mathrm{~m}$ distance from the seismically active Atalanti fault; therefore, the probability of the occurrence 
of an earthquake event when the train crossing the bridge is relatively higher. The Tirothea Domokos bridge has a total length of $505.26(\mathrm{~m})$ and fifteen (15) spans (approx. 34.0m length each) consisting of precast-prestressed beams simply supported on single and multicolumn piers with heights ranging from $2.67(\mathrm{~m})$ to $6.57(\mathrm{~m})$. All multicolumn piers consist of two cylindrical piers supporting the two decks through pot bearings and stoppers. The first five pairs of piers are single column cylindrical (or rectangular) piers (Fig. 3), supporting the deck through pot bearings and stoppers. The abutments are seat type; the seismic gap is considered along the longitudinal direction but not the transverse one to prevent derailment. The bridge is modelled using linear and nonlinear elements and material laws, as described at the relevant section above and depicted in Fig.3.
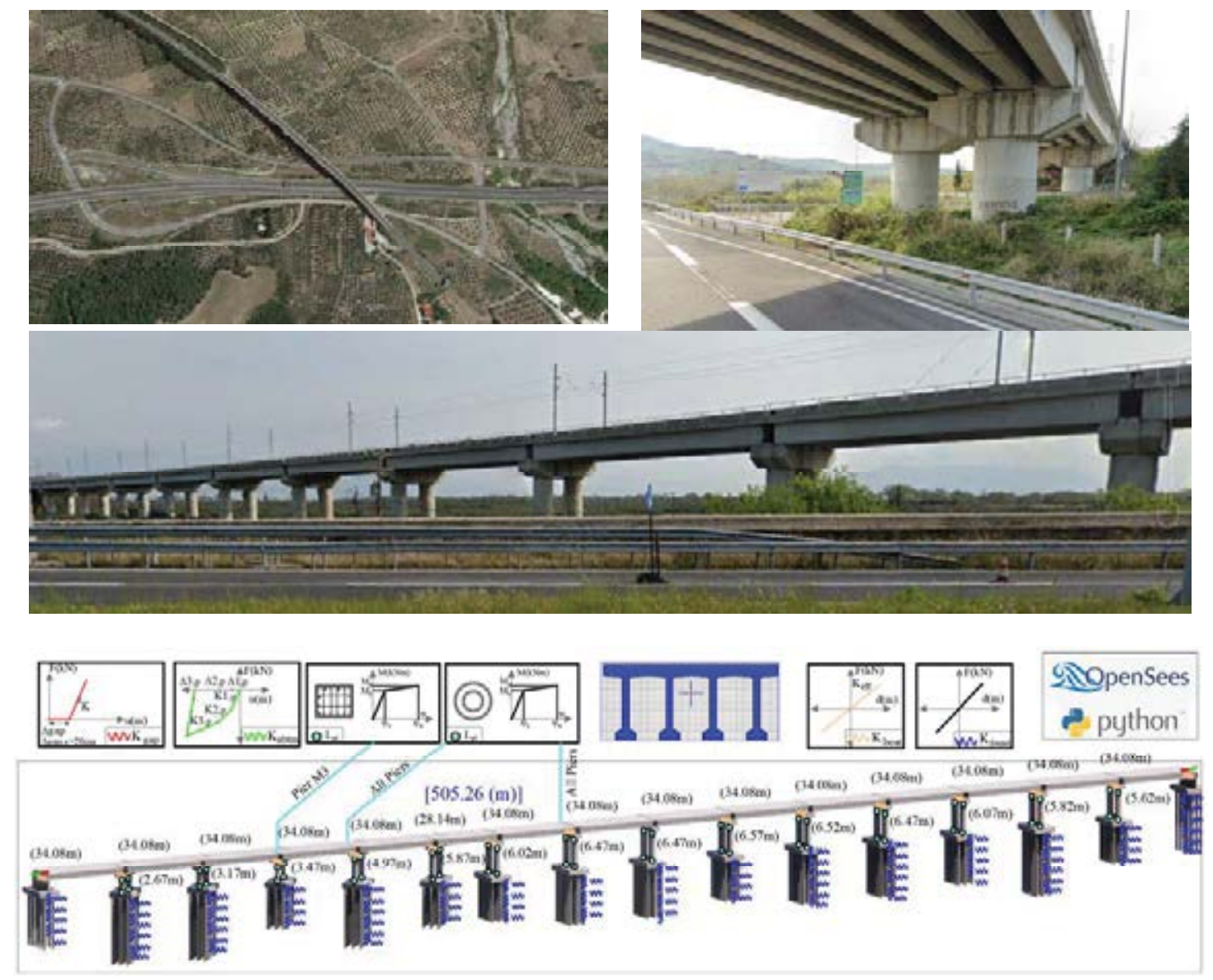

Figure 3: Description of Tirothea-Domokos railway bridge and details of the structural model

Regarding the effect of VBI consideration on the seismic fragility of critical bridge components, it is obvious from Fig.4 that the component seismic fragility (i.e. the probability of damage for different levels of earthquake intensity) is decreased, mainly for higher limit states, in case that the train is considered to move on the bridge during the earthquake and vehiclebridge interaction is accounted for. The latter is attributed to the fact that the consideration of the vehicle during analysis differentiates the dynamic characteristics of the bridge, resulting in a different earthquake response that is additionally related to the structural system and the properties (ductility, inelastic performance, etc.) of the components. 

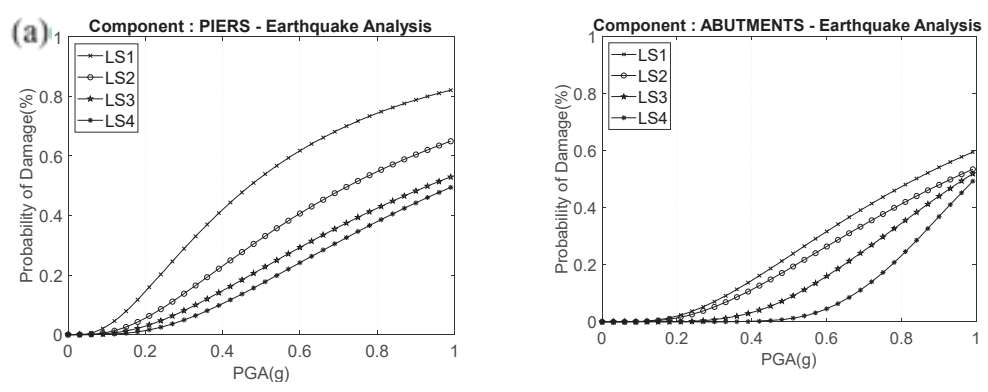

(b)
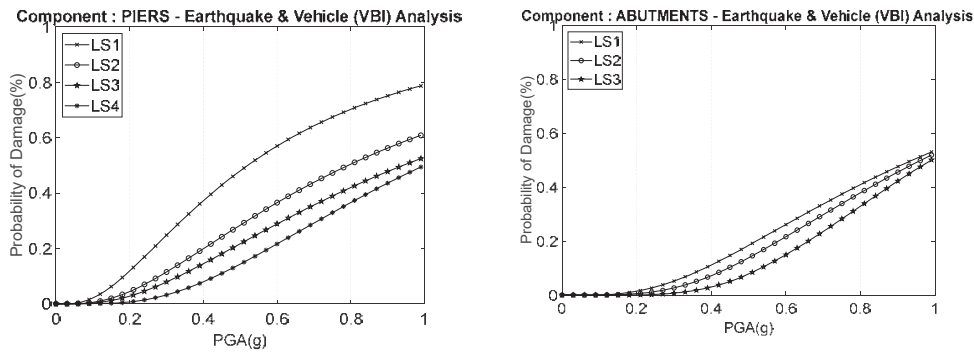

Figure 4: Seismic fragility curves of the critical components of the bridge subsystem with (a) and without (b)VBI consideration for the Tirothea-Domokos Railway Bridge and x-direction
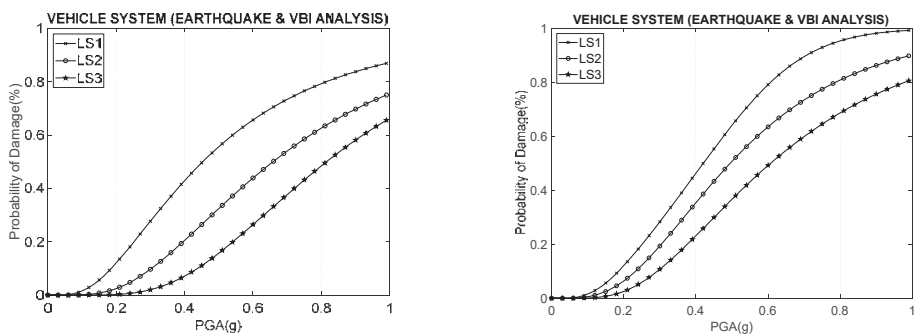

Figure 5: Seismic fragility curves of the vehicle subsystem for the Tirothea-Domokos Railway Bridge (x- and ydirection)

Fragility Curves (X-direction) - Bridge System \& Coupled Bridge-Vehicle System
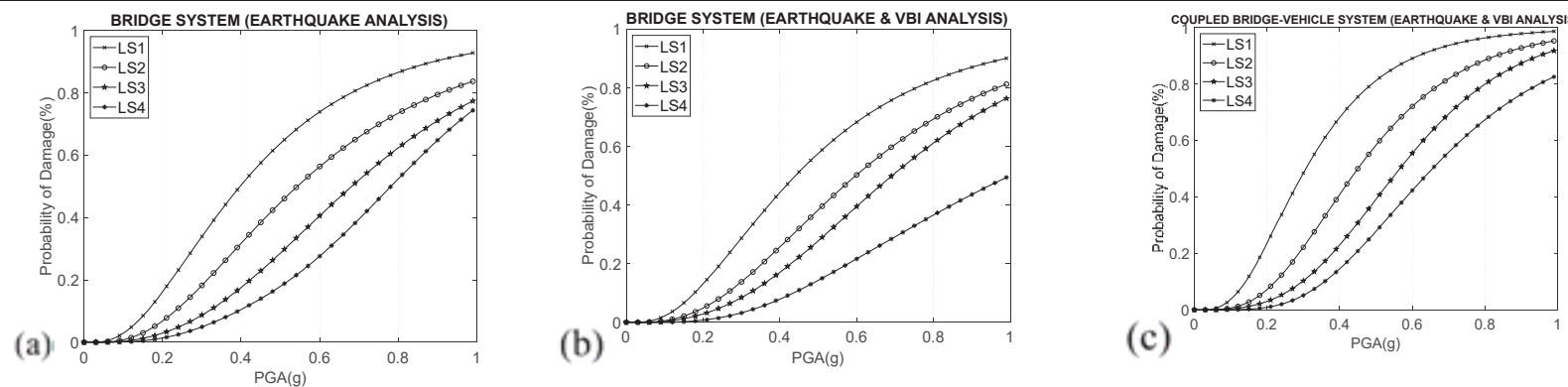

Fragility Curves (Y-direction) - Bridge System \& Coupled Bridge-Vehicle System
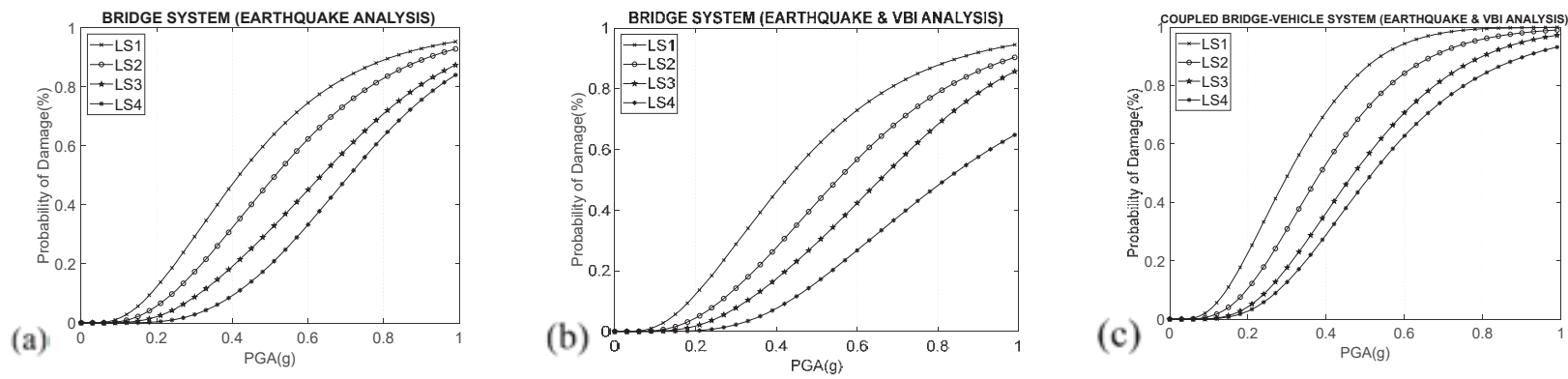

Figure 6: Seismic fragility curves of the bridge subsystem with and without VBI consideration (a,b) and of the coupled train-bridge system with VBI consideration for the Tirothea-Domokos Railway Bridge (x- and y- direction)

Respectively, VBI consideration was found to reduce the seismic fragility of the bridge system and both the longitudinal and transverse direction, compared to the relevant without 
the train movement and VBI consideration. The reduction is greater for the higher limit states and the transverse direction of the bridge and is consistent with the previous comment regarding the effect of VBI on the seismic fragility of components, since series connection is assumed for the estimation of the bridge system's fragility.

The seismic fragility of the vehicle subsystem, i.e. the probability of damage related to the exceedance of the limit state defined for running stability, dynamic bridge performance and running safety, are presented for LS1 to LS3 (same with LS4) in Figure 5. The consideration of the aforementioned limit states in the frame of the coupled system analysis and the derivation of relevant fragility curves is obviously critical, based on Fig.6 (c). The seismic fragility of the coupled vehicle-bridge system for both the longitudinal and transverse direction is obviously higher for all the damage states when the limit states related to the vehicle performance are considered in the frame of fragility analysis (accounting for series connection between subsystems). Therefore, it was found crucial to account for VBI and for limit states related to the vehicle performance for the estimation of the coupled systems' fragility since the system is practically coupled and the train safety, stability, etc affects the total performance. However, for resilience, restoration and loss assessment, all the subsystem and component fragility curves should be considered.

\section{CONCLUSIONS}

A novel methodology for fragility analysis of the coupled vehicle-bridge system is presented herein, accounting for the fragility of subsystems (vehicle and bridge). Limit state thresholds are defined at component and subsystem level and the probabilistic framework is applied, analyzing the coupled system on the basis of a co-simulation technique. A fully parameterized, software is developed including a tailor-made module for vehicle analysis (multibody system), the use of an open-source software for bridge analysis and a module developed for fragility analysis based on the proposed framework. The methodology and framework proposed are applied to a representative, simply supported bridge of the Greek railway network, providing the coupled systems' fragility curves. The most important conclusions from the application of the methodology to the case study bridge are summarized below:

- The seismic fragility of critical bridge components is decreased for the case that VBI is considered, mainly for higher limit states. The latter is attributed to the differentiation of the dynamic characteristics of the bridge due to VBI resulting in a different earthquake response, also related to the structural system and the properties (ductility, inelastic performance, etc.) of the components.

- VBI consideration was found to reduce the seismic fragility of the bridge system and both the longitudinal and transverse direction, compared to the relevant without the train movement and VBI consideration. The reduction is greater for the higher limit states and the transverse direction of the bridge.

- The seismic fragility of the coupled vehicle-bridge system for both the longitudinal and transverse direction is higher for all the damage states when the limit states related to the vehicle performance are considered. Therefore, it was found crucial to account for VBI and for limit states related to the vehicle performance for the estimation of the coupled systems' fragility. 


\section{ACKNOWLEDGEMENTS}

The authors would like to thank ERGOSE SA \& METESEISM SA for providing access to the data (drawings, technical reports) of the case study bridges.

This project has received funding from the Hellenic Foundation for Research and Innovation (HFRI) and the General Secreteriat for Research and Innovation (GSRT), under grant agreement No 617"

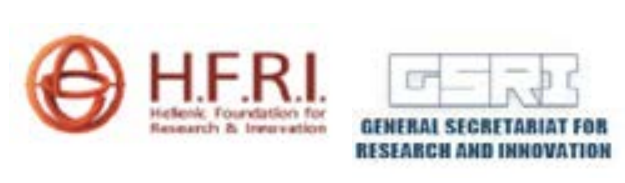

\section{REFERENCES}

[1] H. Xia, N. Zhang, N., W.W. Guo, Dynamic Interaction of Train-Bridge Systems in High-Speed Railways. Springer-Verlag, 2018.

[2] A.A. Shabana, K.E. Zaazaa, H. Sugiyama, Railroad Vehicle Dynamics: A Computational Approach. Flexible Multibody Dynamics. CRC Press, 2010.

[3] Q. Zeng, and E.G. Dimitrakopoulos, Vehicle-bridge interaction analysis modeling derailment during earthquakes. Nonlinear Dynamics, 93-4, 2315-2237, 2018.

[4] Q. Zeng, C.D. Stoura, E.G. Dimitrakopoulos, A localized lagrange multipliers approach for the problem of vehicle-bridge-interaction. Engineering Structures,168,82-92, 2018.

[5] Y.E. Wu, Y.B. Yang, J.D. Yau, Three-Dimensional Analysis of Train-Rail-Bridge Interaction Problems. Vehicle System Dynamics, 36-1, 1-35, 2001.

[6] X.Y. Lei, High Speed Railway Track Dynamics. Models, Algorithms and Applications. Springer Verlag, 2017.

[7] C. D. Stoura, E. Paraskevopoulos, E.G. Dimitrakopoulos \& S. Natsiavas. A Dynamic Partitioning Method to solve the vehicle-bridge interaction problem. Computers and Structures, 251, 2021.

[8] T.S. Paraskeva, E.G. Dimitrakopoulos, Q. Zeng, Dynamic vehicle-bridge interaction under simultaneous vertical earthquake excitation. Bull. Earthquake Eng, 15, 71-95, 2017.

[9] Y.F. Mechmet, C.O. Barlas, Seismic assessment of a multi-span steel railway bridge in Turkey based in nonlinear time history. Nat. Hazards Earth Syst. Sci, 18, 231-240, 2018.

[10] E. Paraskevopoulos, S. Stefanidou, S. Natsiavas, (2019). A novel approach for the analysis of a coupled train-railway bridge system: Basic Principles and Methodology. 7th ECCOMAS Thematic Conf on Computational Methods, COMPDYN 2019, 24-26 June, Crete, Greece.

[11] E. Paraskevopoulos, S. Natsiavas. On applications of Newton's law to mechanical systems with motion constraints. Nonlinear Dynamics, 72 (1-2), 455-475, 2013

[12] S. Natsiavas, E. Paraskevopoulos. A set of ordinary di erential equations of motion for constrained mechanical systems. Nonlinear Dynamics, 79(3), 2015. 
[13] M. Zhu, F. McKenna, \& M. H. Scott, OpenSeesPy: Python library for the OpenSees finite element framework. SoftwareX, 7, 6-11., 2018

[14] F. Naeim, \& J. M. Kelly, Design of Seismic Isolated Structures. John Wiley \& Sons, INC., U.S.A., 1999.

[15] Zhang, J., \& Huo, Y. Evaluating effectiveness and optimum design of isolation devices for highway bridges using the fragility function method. Engineering Structures, 31(8), 1648-1660, 2009.

[16] Stefanidou, S.P., Sextos, A. G., Kotsoglou, A. N., Lesgidis, N., \& Kappos, A. J., Soilstructure interaction effects in analysis of seismic fragility of bridges using an intensitybased ground motion selection procedure. Engineering Structures, 151, 366-380, 2017.

[17] Stefanidou, S.P., \& Kappos, A. J. Methodology for the development of bridge-specific fragility curves. Earthquake Engineering \& Structural Dynamics, 46, 73-93, 2017.

[18] Olivier, B., Verlinden, O., \& Kouroussis, G. Effect of applied force cosimulation schemes on recoupled vehicle/track problems. Multibody System Dynamics, 50(4), 337353, 2020 